\title{
CHANGES IN THE STATISTICAL PROPERTIES OF THE INDONESIAN STOCK EXCHANGE INDEX TROUGH FIVE DIFFERENT TIME PERIODS SINCE 1998 UNTIL 2016
}

\author{
NOWO RIVELI*, ASWAD HI SAAD, LIU KIN MEN, BAMBANG J SUROTO \\ Departemen Fisika Fakultas MIPA Universitas Padjadjaran, \\ Jl. Raya Bandung-Sumedang Km 21, Jatinangor 45363 \\ *email : nowo@phys.unpad.ac.id
}

\begin{abstract}
Abstrak. Metode sederhana berdasarkan Uji Kolmogorov-Smirnov telah diterapkan pada data harian Indeks Harga Saham Gabungan (IHSG), untuk mengidentifikasi periodisasi waktu yang terjadi dalam kurun waktu dari tahun 1998 sampai 2016. Ditemukan lima segmen periode waktu, dimana pada masing - masing periode tersebut distribusi IHSG menunjukkan sifat statistik yang berbeda. Sifat statistik tersebut ditentukan dari nilai rata - rata dan varian dari fungsi Levy-stable yang di fit terhadap data distribusi IHSG di tiap periode yang ada.
\end{abstract}

Kata kunci : IHSG, fungsi Levy-stable, Uji Kolmogorov-Smirnov

\begin{abstract}
A simple method based on Kolmogorov-Smirnov Test were applied to the Indonesian Stock Exchange Index (IHSG) daily log return distribution to identify it's time segmentation . Five separated periods were found from the overall data since July 1997 until May 2016. Distribution of the daily log return price from each time periods are characterized by two shape parameters of the fitted Levy-stable function, where the parameters are directly related to the variance and skewness of the distribution. The resulting time segmentations does indeed show systematic differences on the evolution of the daily index price, and the varying two fit parameters of the daily return distribution can be used to explain such diverse behavior.
\end{abstract}

Keywords : IHSG, fungsi Levy-stable, Uji Kolmogorov-Smirnov

\section{Introduction}

In the field of financial economy, the stock market can be regarded as a complex system. The fluctuations of the stock price index are unpredictable and deemed to be dependent on a large number of different variables. They could be the qualitative ones such as political situations and changes in policy, and the quantitative ones such as changes in currency rates and changes in the interest rates. To describe and analyze such kind of behavior, it is believed that the tools and methods in statistical physics are potentially useful [1-5].

In Indonesia, there has been an effort of using statistical physics to study the variations in stock price index [6,7]. In those studies, the authors analyze the distributions of the Indonesian stock exchange index (IHSG), in the time span that includes before, during, and after the 1997 monetary crisis. The main finding is, that there are changes in the statistical properties of the index distribution in those three different time periods. It is then used as an argument that the monetary crisis indeed causes a change in the behavior of the financial market in Indonesia. The 
conclusion that we would like to highlight is, that the methods in statistical physics can and have been used to identify a principal changes in structure of the financial market, particularly in Indonesia. This then can be used to further diagnose the factors that might be linked to the transformation of a financial market.

It is of our interest to perform such investigation up to recent time. In particular, we are searching for different time periods, where there are substantial changes in the behavior of the financial market in Indonesia. The changes in the behavior of the financial system, are represented by the differences of the statistical properties of the stock price index distributions, in each time periods. For that purpose, we collect IHSG index price data recorded from July 1997 to May 2016. In examining the financial market behavior, we evaluate the distributions of the price return index, defined as:

$$
z_{\Delta \mathrm{t}}(t)=\ln Y(t+\Delta t)-\ln Y(t)
$$

Where $Y$ is the index price value. In particular, we are examining the daily return index where $\Delta t=1$ day. Many empirical studies shows that the distribution of the price return index behave like a heavy tailed bell-shaped curve [8-10], and that it can be fitted to a Levy-stable distribution [6,7], this was first proposed by Mandelbrot [5]. Nevertheless, other types of distributions have also been used to describe the price return index, including the Gaussian function [6,7,11]. As a nice bookkeeping of different fitting approach to the price return index, as well as an effort to provide a standard, one can refer to Ref. [11].

The different time periods that we are looking for will be separated by several dates that we call as the changing points. Naturally, one can make the relations between the change of the financial situations, with any major events that took place around the changing point dates. In the earlier work $([6,7])$ the changing points are determined a priori as the dates when the Indonesian Rupiah currency rates fall very steeply. It is the aim of our study, to find the changing points without any assumptions based on any socio-economic situations. Instead, we develop a brute force algorithm that depends solely on the stock index data, and would automatically discover the most probable changing point dates.

\section{Methode}

The identification of the statistically different time periods are performed in two steps. The goal of the first step is to find the number of possible time periods, while the goal of the second step is to locate the best position for the changing points between all time periods. In all parts of the procedure, we utilize the KolmogorovSmirnov test [13] to find the likelihood that two samples are drawn from the same continuous distribution.

In the first step, a candidate of a time segment is formed by a moving variable date. Each time the variable date change its position, Kolmogorov-Smirnov test is performed between the return price distributions from two adjacent time segments. When the resulting Kolmogorov-Smirnov probability reach a value below a certain threshold, the scanning is stopped and a separated time segment is set. The procedure is then followed by searching for the next time segment. Scanning in both directions (start from left and start from right) were performed. 
In the second step, the starting changing points found from step 1 is adjusted so to find the minimum sum of Kolmogorov-Smirnov probabilities. Each changing points are moved randomly to the left and right within a certain time window. A set of changing points that gives the least Kolmogorov-Smirnov probabilities sum is set as the new starting points. The method is iterated with narrowing time window around each changing points. Iteration is stopped when the total KolmogorovSmirnov probabilities did not go to a lower value. One can see that such simple procedure does not provide a guarantee that the final set of changing points are the ones that would give the true minimum Kolmogorov-Smirnov probabilities sum. Therefore a further scan is taken where variable dates are moved in every 1-day step, within a certain region around the attained changing points.

By operating the procedures above, we obtained in total of five separated time periods. Location of the changing points are shown in Fig. (1). Values of the Kolmogorov-Smirnov probability between different time periods are shown in Table. 1.

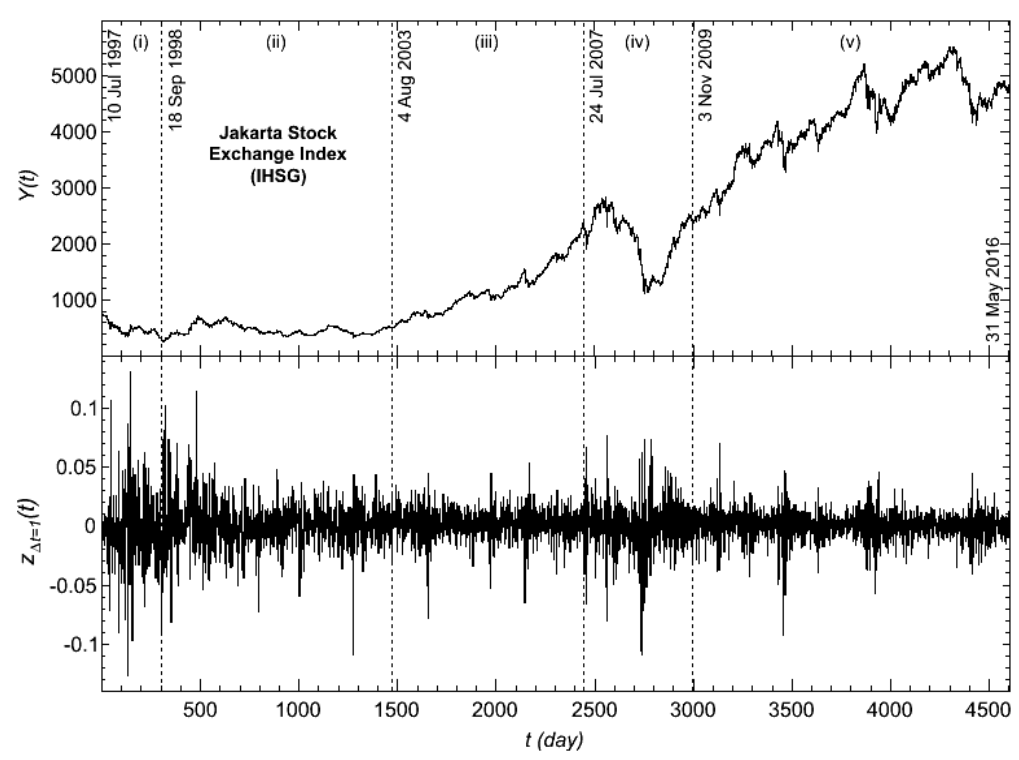

Fig. 1. Daily index price fluctuation (top) and daily index return (bottom), divided into five time periods with minimum Kolmogorov-Smirnov probability values between adjacent distributions.

Table 1. Kolmogorov-Smirnov Test probability values between distributions of the daily return index from two different time periods

\begin{tabular}{cccccc}
\hline $\begin{array}{c}\text { time } \\
\text { segment }\end{array}$ & \multicolumn{1}{c}{ i } & \multicolumn{1}{c}{ ii } & \multicolumn{1}{c}{ iii } & \multicolumn{1}{c}{ iv } & \multicolumn{1}{c}{ v } \\
\hline i & 1 & $6.63 \mathrm{E}-07$ & $8.80 \mathrm{E}-14$ & 0.000395 & $6.22 \mathrm{E}-15$ \\
ii & $6.63 \mathrm{E}-07$ & 1 & $3.81 \mathrm{E}-08$ & 0.108 & $5.64 \mathrm{E}-07$ \\
iii & $8.80 \mathrm{E}-14$ & $3.81 \mathrm{E}-08$ & 1 & $2.50 \mathrm{E}-06$ & 0.001643 \\
iv & 0.000395 & 0.108 & $2.50 \mathrm{E}-06$ & 1 & $6.90 \mathrm{E}-07$ \\
v & $6.22 \mathrm{E}-15$ & $5.64 \mathrm{E}-07$ & 0.001643 & $6.90 \mathrm{E}-07$ & 1 \\
\hline
\end{tabular}




\section{Results and Discussion}

In this study, all the price return index from each time segment are to be fitted to the Levy-stable distribution, which has four parameters $\alpha, \beta, \gamma, \delta$. The fitting is completed based on the Maximum-likelihood fitting of univariate distributions. $\alpha$ and $\beta$ are shape parameters, where they respectively governs the spread and symmetry of the distribution. A Gaussian distribution is a special case of the stable distribution, with values $\alpha=2$ and $\beta=0$. While $\gamma$ and $\delta$ determine the scale and position of the distribution.

The fit parameters of the distributions from all time segments are presented in Table 2. The fitting function plotted against the histogram of the distribution is shown in Fig. 2. We noted that the parameter $\delta$ from all time segment does not depart very much from zero. On the other hand, variation of the $\gamma$ parameter can be removed by normalization. Therefore, we will be using only the shape parameters $\alpha$ and $\beta$ in characterizing the statistical properties of the index return distribution from each time segment.

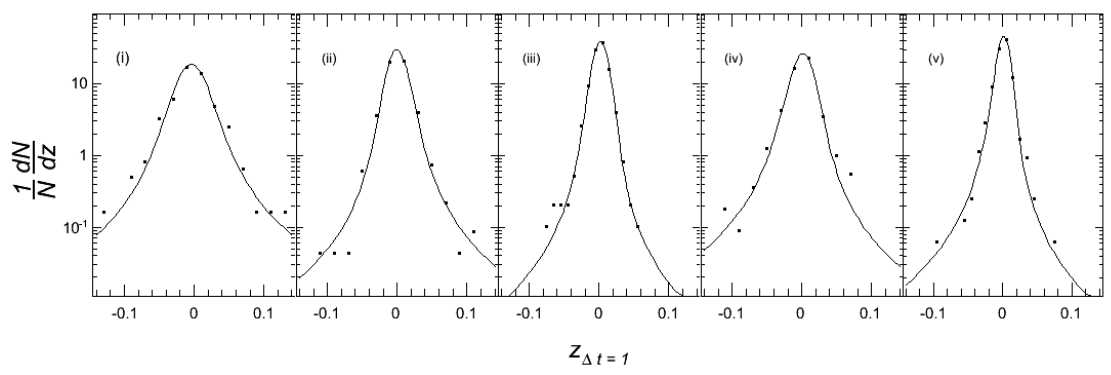

Fig. 2. Distribution of the daily index return from five time periods (dotted) and their fitting function (line).

Table 2. Levy-stable fit parameter values of the daily return distribution from five time periods.

\begin{tabular}{ccccccccc} 
time segment & $\alpha$ & $\Delta \alpha$ & $\beta$ & $\Delta \beta$ & $\gamma$ & $\Delta \gamma$ & $\delta$ & $\Delta \delta$ \\
\hline i & 1.54 & 0.11 & 0.06 & 0.16 & 0.0155 & 0.0011 & -0.0041 & 0.0015 \\
ii & 1.63 & 0.05 & 0.18 & 0.10 & 0.0095 & 0.0003 & -0.0004 & 0.0004 \\
iii & 1.76 & 0.05 & -0.20 & 0.16 & 0.0073 & 0.0002 & 0.0022 & 0.0004 \\
iv & 1.57 & 0.06 & -0.25 & 0.13 & 0.0108 & 0.0005 & 0.0015 & 0.0008 \\
v & 1.62 & 0.04 & -0.33 & 0.08 & 0.0061 & 0.0002 & 0.0015 & 0.0002 \\
\hline
\end{tabular}

Since $\alpha$ governs the spread of the distribution, it can be related to the variance of the distributions. This number then will give us how far a closing index price in a certain day, can fluctuate from the previous day. In financial economy, such variable is closely related to the volatility of the market. Whereas for $\beta$, it controls the trend of the index price changes, either up, flat or down. A $\beta$ value that is far from zero, means that the index price have an increasing trend, if it is negative, and a decreasing trend, if it is positive.

To further examine the statistical properties of the price return distribution from each time segment, we calculated the variance and skewness of the fitted 
distribution function. Ideally, a Levy-stable function possesses an infinite variance. A more useful finite variance is obtained by performing a cut on the range of the return variable. Here we put the cut at $z= \pm 0.2$ for every time segment. The variances are plotted against the $\alpha$ value (Fig. 3), while the skewness are plotted against $\beta$ (Fig. 4). We found that the variance are related inversely and non-linearly to $\alpha$, while skewness is simply proportional to $\beta$.

Table 3. Variance and Skewness of the Levy-stable fit function of five time periods.

\begin{tabular}{ccr} 
time segment & \multicolumn{1}{c}{ var } & skewness \\
\hline i & 0.002776 & 0.78 \\
ii & 0.000896 & 3.23 \\
iii & 0.000321 & -4.32 \\
iv & 0.001422 & -4.02 \\
v & 0.000462 & -8.50 \\
\hline
\end{tabular}
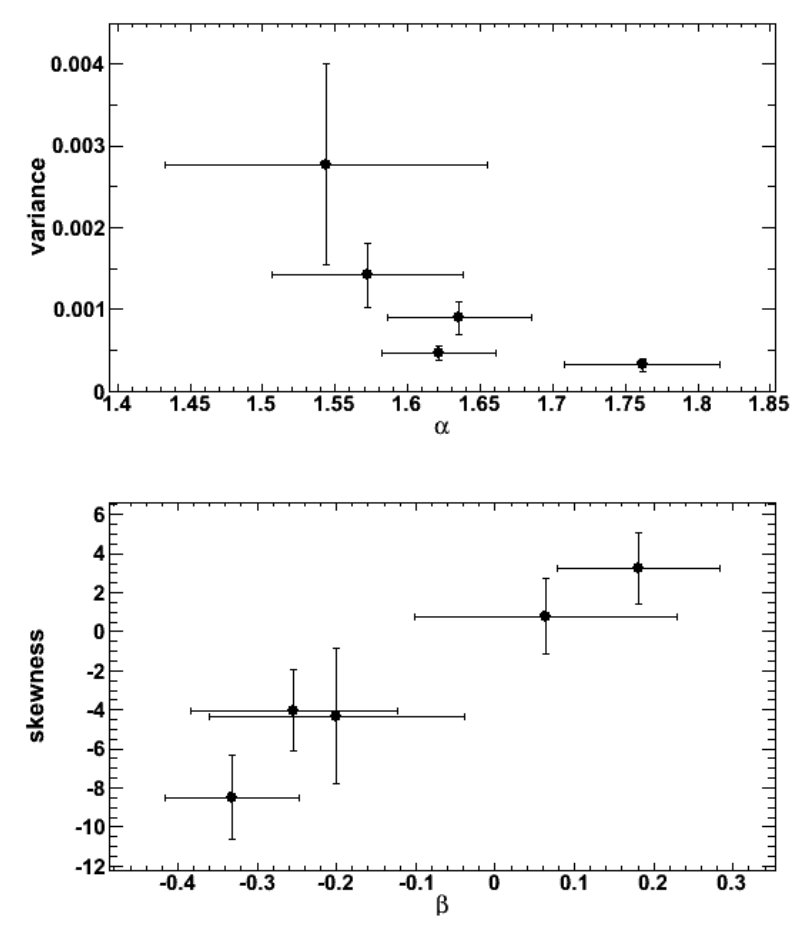

Fig. 3. Variance vs $\alpha$ (top) and skewness vs $\beta$ (bottom) of the Levy-stable fit function of five time periods.

From the relation between the shape parameters with variance and skewness, we can make sense the behavior of the daily index price evolution from the $\alpha$ and $\beta$ values. In time segment (i), $\alpha$ is small and $\beta$ is small, this manifested in a rather stationary evolution of the index price by day. In time segment (ii), $\alpha$ is large and $\beta$ is not too small. A positive $\beta$ value that is rather far from zero would be translated to a decresing trend of the index price, but a large $\alpha$ allowed the fluctuation to take a large step opposite to the suggested trend, thus produces a quite constant behavior of the index price. In time segment (iii) and (v), $\alpha$ are rather small while $\beta$ are 
largely negatives. This condition manifest in a positive trend of the index price without too much disruption. And last, time segment (iv), both it's $\alpha$ and $\beta$ are large, almost like in segment (i), but with much greater $\beta$. We notice that overall the index price in this time segment shows a positive trend, in agreement with the large $\beta$. But it undergoes a big jump in the process, as anticipated by the large $\alpha$.

\section{Conclusions}

In this study, we have identified five-time periods in Indonesia that systematically have different behavior in terms of stock market system. The differences are discovered by finding the minimum value of Kolmogorov-Smirnov Test probability between the distributions of daily return index from adjacent time segment. Furthermore, we have characterize the statistical properties of the index return distribution with two shape parameters of the Levy-stable distribution, $\alpha$ and $\beta$. Variation of $\alpha$ and $\beta$ from all time segment can then be used to explain the different behavior of index price fluctuation, of each time segment.

\section{References}

1. R.N. Mantegna, H.E. Stanley, An Introduction to Econophysics, Cambridge University Press, Cambridge, UK, (2000).

2. S. Sinha, A. Chatterjee, A. Chakraborti, B.K. Chakrabarti, Econophysics: An Introduction, Wiley-VCH, Berlin, Germany, (2010).

3. V. Pareto, Cours d' Economie Politique, Lausanne and Paris (1897).

4. P. L'evy, Th'eorie de l'Addition des Variables Al'eatoires, Gauthier-Villars, Paris (1937).

5. B. B. Mandelbrot, The variations of certain speculative prices, J. Business Vol 36 Issue 294 (1963) p. 394-419.

6. T. Mart, Y. Surya, Statistical properties of the Indonesian Stock Exchange Index, Physica A Vol. 344 (2004) p. 198-202.

7. T. Mart, T. Aminoto, Impact of the monetary crisis on statistical properties of the Jakarta and Kuala Lumpur stock exchange indices, Physica A Vol. 373 (2007) p. 634-650.

8. R. N. Mantegna and H. E. Stanley, Scaling behaviour in the dynamics of an economic index, Nature Vol. 376 (1995) p. 46.

9. J.P. Bouchaud and D. Sornette, The Black-Scholes option pricing problem in mathematical finance: Generalization and extensions for a large class of stochastic processes, J. Phys. I (France) Vol. 4 (1994) p. 863.

10. D. Sornette, A. Johansen, and J.-P. Bouchaud, Stock Market Crashes, Precursors and Replicas, J. Phys. I (France) Vol. 6 (1996) p. 167.

11. Chandradew Sharma, Kinjal Banerjee, A study of correlations in the stock market, Physica A Vol. 432 (2015) p. 321-330.

12. G. Bucsa, F. Jovanovic, C. Schinckus, A unified model for price return distributions used in econophysics, Physica A Vol. 390 (2011) p. 3435-3443.

13. Chakravarti, Laha, and Roy, Handbook of Methods of Applied Statistics, Volume I, John Wiley and Sons (1967) p. 392-394. 